\title{
An international approach to the famous glacial islands
}

BERNARD McGuiRK

RESENHA: ERLICH, Uriel. Malvinas: soberanía y vida cotidiana. Villa María, Argentina: Eduvim, 2015.

"War changes everything. The matter is closed". Thus is the standard official response of United Kingdom spokespersons when invited to discuss, let alone enter dialogue much less negotiation with, Argentine - or other - would-be interlocutors, regarding the issue of sovereignty over the Falklands-Malvinas. In sum, the door is hardly open and the mind is ostensibly closed. London speaks not. Nonetheless, it is not just in Argentina that interest both in a disputed sovereignty and, more broadly, in the territory both geographic and metaphoric of the "too famous glacial islands", in the classic formulation of Jorge Luis Borges, continues to be manifested.

Even as I write, from a British base if not from a closed perspective, books and articles, academic and journalistic, conferences and workshops, research projects and internet debates proliferate. Perspectives shift, predictably, nearly forty years on from the 1982 conflict in the South Atlantic. Whether on the British side, studies on the recently released government (including Thatcher) official, however redacted, documents, books of military memoirs or analyses of the prevailing mentalities of the early 1980s or, in Argentina, perhaps more urgently, publications that seek to go beyond the pleas that have fallen on deaf ears by broaching topics other than, but not excluding, sovereignty, the polemic will not lie down, let alone be put to bed.

A prime example of an ambitious attempt to address multiple contextual issues of Argentina's reliance on world, and specifically United Nations, support for a general politics of decolonization, and of the United Kingdom's blanket opposition to such discussions, is

\section{$\overline{\text { Bernard McGuirK }}$}

Professor Emeritus of Romance Literatures and Literary Theory, University of Nottingham. President of the International Consortium for the Study of PostConflict Societies. Author of Falklands-Malvinas: An Unfinished Business, New Ventures (Seattle), 2007. E-mail: bernard.mcguirk@nottingham.ac.uk. 
Uriel Erlich'sMalvinas: soberanía y vidacotidiana. Its initial panoramic summary of fifty years of Argentine positionings, thorough and objective historically speaking, gives way to a fresh and broadly overlooked other dimension. For Erlich, the focus is on analysing Argentine policies in their shifting historical contexts, including revelation of the voices and insights of respective decision makers in successive administrations. Inseparably, he brings into sharp focus the views and indeed lives of descendants of Malvinas-born individuals and their families thereby, and vitally, re-interrogating Argentine policies and policymakers of the last half century.

In 1965, Resolution 2065 of the General Assembly of the United Nations triggered the first bi-lateral negotiations over the said Islands, South Georgia, South Sandwich and the surrounding maritime areas. Erlich's strategy depends on interviews that allow interested parties to speak for themselves. His study opens the ears of those who, often, might hear but not necessarily listen to preoccupations and ambitions both historically situated and still urgent for all who would aspire to understand why the matter is not closed and only illusorily bracketed out: "None so deaf as those who will not hear" as the old saying goes. Let there be no doubt, the strongly contrasting phases addressed by Erlich's book, basically the 1990s rapprochement and the 2003-2015 reaffirmation of sovereignty claims and insistence on negotiation, have been and are being heard in London and beyond.

One awaits the next step and Erlich's pursuing of the curious if predictable overtures of such as the then Prime Minister David Cameron or ex-Foreign Secretary Boris Johnson since the election of Mauricio Macri. "Let's negotiate... but, of course, as hombres de negocios", you can hear them say. "Economies rule the airwaves, so let's make waves that matter, as 'fake' politicians disappear, and as 'our' truths align with those emerging, with unprecedented noise, from Washington... and throughout the Americas today". Amidst the current ebbing of the "pink tide" such surface-deep posturings are the obvious flotsam and jetsam of opportunist politicians who, caveat emptor, are themselves readily discarded. Such books as that of Uriel Erlich go deeper. The echo-chamber of both history and serious listening to other voices, authentic and with no little passion, reminds us of the potential and rarely more urgent need, for resistance. 